\title{
Cuba, Galdós y la crisis del 98
}

\section{Cuba, Galdós and the Crisis of 1898}

\author{
IGNACIO URÍA \\ Universidad de Alcalá \\ Facultad de Filosofía y Letras \\ Departamento de Historia y Filosofía \\ c/ Colegios, 2 , \\ 2880I, Alcalá de Henares (Madrid) (España) \\ ignacio.uria@uah.es
}

iD

RECIBIDO: ENERO DE 2021 ACEPTADO: FEBRERO DE 202

Resumen: Este artículo analiza el influjo de Cuba en la vida y en la obra de Benito Pérez Galdós, ya sea en su producción periodística o literaria. La emigración española al Caribe, las guerras de Cuba y, en particular, la derrota de 1898, son asuntos recurrentes en su obra, así como el papel jugado por Estados Unidos en la desaparición de las últimas posesiones ultramarinas españolas o la amenaza del imperialismo norteamericano para la cultura hispánica de América. En Galdós, por tanto, convivieron la importancia de la Isla para España en el siglo XIX, el impacto de su pérdida y la simpatía por el proyecto político cubano (liberal, laico y reformista).

Palabras clave: Galdós. Cuba. Crisis del 98. Colonias españolas. Guerra de Cuba.

Abstract: This paper analyzes the powerful influence of Cuba on the life and work of Benito Pérez Galdós, whether in his journalistic or literary production. Spaniard emigration to the Caribbean, the wars in Cuba and, in particular, the defeat of 1898, are recurring themes in his work, as well as the role played by the United States in the disappearance of the last Spanish overseas possessions and the threat of North American imperialism to the Hispanic culture of America. Galdós, therefore, coexisted with the importance of the Island for Spain in the $19^{\text {th }}$ century, the impact of its loss and sympathy for the Cuban political project (liberal, secular and reformist).

Keywords: Galdós. Cuba. Crisis of 1898. Spanish Colonies. War of Cuba 


\section{IGNACIO URÍA}

En la ingente cantidad de estudios sobre Benito Pérez Galdós merece una revisión su posición literaria y política sobre la pérdida de Cuba -y también, aunque en menor medida, de Puerto Rico y Filipinas, calificadas habitualmente como las últimas colonias españolas cuando ni eran colonias strictu sensu ni fueron las últimas 1 - y el impacto que produjo en la sociedad española y en la propia vida del escritor canario.

1898 fue un año clave en la historia de España por la derrota en la guerra contra Estados Unidos, el fin del Imperio y el cuestionamiento de la identidad nacional y la reflexión sobre el futuro del país. También para Galdós se convirtió en un momento muy importante, ya que ese año retomó los Episodios Nacionales después de dos décadas sin publicar ninguna novela de la colección.

En su vida personal, como veremos, Cuba tiene una presencia permanente, pero también en su obra literaria la Isla aparece una y otra vez, ya sea destino de militares dispuestos a ascender por méritos de guerra, emigrantes ambiciosos o nobles arruinados deseosos de enriquecerse ${ }^{2}$. Quizá el más paradigmático sea el advenedizo José María Manso - hermano de Máximo, el protagonista de El amigo Manso, 1882-, llegado de La Habana con su esposa cubana, Lica, tras la guerra de I868. A ella la despreciarán en Madrid por ser demasiado ruda, personaje que molestó al escritor y líder independentista cubano José Martí al considerarla una «excepción» entre la señorial clase alta criolla: «¿Qué sabe él [Galdós], ni España qué sabe, de lo que los cubanos son $[\ldots]$ ?.»3 .

Sin embargo, don Benito sí conocía a los cubanos, tanto por experiencia personal como por su constante interés en la actualidad ultramarina. Sobre todo, la cubana, posesión para que la que deseaba más autonomía, tal y como escribió en La Prensa de Buenos Aires4.

\section{Cuba en la Vida PeRsonal de Benito Pérez Galdós}

Cuba había estado presente en la vida de Galdós desde muy joven por motivos familiares - tres tíos carnales y tres hermanos suyos vivieron en la Isla,

\footnotetext{
I España mantuvo hasta 1899 los archipiélagos asiáticos de las Marianas y las Carolinas en Micronesia y, hasta la segunda mitad del siglo XX, los territorios africanos de Marruecos, Guinea Ecuatorial y el Sáhara.

2 García Barrón, 1986, p. 146.

3 Pacheco González, 2015, p. 15.

${ }^{4}$ «Si las reformas fuesen tan sabias y profundas que transformasen el modo de ser político y jurídico de aquel país, las dificultades [de Cuba] estarían salvadas en gran parte. [...] ¿Cuándo te dejarán en paz? ¿Cuándo te permitirán gozar de lo tuyo y ser dueña de [...] de tu propio suelo? Es terrible que no puedas removerte, sin que al punto resuenen en Europa y América lamentos y protestas». «Cuba-Filipinas», La Prensa, 9 de diciembre de 1884.
} 
además de tener tres cuñados cubanos- como por la estrecha relación de su tierra, Canarias, con Cuba debido a la nutrida emigración ${ }^{5}$.

Sin embargo, antes de entrar a analizar estos vínculos, debo aclarar un error repetido que señala que su abuelo materno, Domingo Galdós de Alcorta, habría sido el primero de su linaje que residió en Cuba. Esto es incorrecto, ya que Domingo Galdós - hidalgo guipuzcoano venido a menos- jamás vivió en La Habana. A don Benito, sin embargo, le gustaba presumir de ese abuelo, al que se refería jocosamente como «el inquisidor», cuando este no pasó de ser un simple cobrador de multas del Santo Oficio en Las Palmas ${ }^{6}$. De hecho, Domingo no llegó a Las Palmas como funcionario de la Inquisición, sino acompañando a un familiar, Francisco Javier Ysuriaga, juez de la Audiencia de las Islas ${ }^{7}$.

¿De dónde procede el malentendido? Posiblemente de un bisabuelo canario llamado Juan Antonio Medina - padre de la abuela paterna del escritor-, que en I77I emigró a las Indias. En aquella época, gran número de isleños se iban para La Habana ${ }^{8}$, tanto por la semejanza climática como por la amplia colonia canaria. De ahí puede proceder el error, aunque no haya constancia documental -al menos yo no la he encontrado- de que Medina efectivamente emigrara a la Isla.

La referencia de su bisabuelo resulta muy lejana, pero no así la de tres tíos suyos, Domingo, Manuel y José María de Galdós, que vivieron muchos años en Cuba. Domingo, militar en Santa Clara; Manuel, abogado de la Real Audiencia de La Habana, y José María, asesor militar de la Comandancia Central de Cuba. Este se afincó en Trinidad, población de la que llegó a ser alcalde en 1872 y al que dedicaron una céntrica calle que hoy perdura y en la que actualmente se ubican las oficinas del Conservador de la Ciudad.

Esta vinculación la reforzaron más tarde tres hermanos de mayor edad: Domingo y Sebastián, que emigraron a La Habana —el primero por razones de salud; el segundo, para hacer fortuna- $y$, sobre todo, Ignacio, militar residente en Cuba durante casi dos décadas y muy unido al escritor pese a los ocho años de edad que los separaban. Además de ellos, tres cuñados de don Benito eran cubanos: José Hurtado de Mendoza (marido de su hermana Carmen), Magdalena Hurtado de Mendoza (esposa de Domingo y hermana del anterior), madrina del

\footnotetext{
${ }^{5}$ Existen dos archivos de los Galdós en Estados Unidos: el Archivo de la Familia Galdós en Fairfield (lowa) y el Archivo Familiar de Massachusetts (AFM). Armas Galdós, 2015, 387.

${ }^{6}$ Artiles, 1967, p. 162.

7 Sobre esta cuestión, Camacho, 1973, pp. 575-629. La rama que más tiempo permaneció en Cuba fue la de Domingo Galdós, hasta 1961. Armas Ayala, 201 I, pp. 787-796.

${ }^{8}$ El 83 por ciento de los canarios que emigraron a América en el siglo XIX lo hicieron a Cuba. Guanche, 1983, p. 37.
} 
escritor y financiadora de su primera novela, La Fontana de Oro, publicada en 1870. Por último, la santiaguera Caridad Ciria y Vinent, casada con su hermano Ignacio y, junto a Magdalena Hurtado, a la que más trató.

A nivel personal, el impacto de la isla caribeña se acrecentó gracias a su prima María Josefa Galdós Tate, Sisita. Esta había llegado a Las Palmas en 1850 siendo una niña cuando su padre, José María, envió definitivamente a Canarias a toda su familia debido a la violencia que asolaba Trinidad'.

Un año menor que Benito, «la prima Sisita» se convirtió en su amor adolescente, situación incómoda para los Galdós porque ella le correspondía. La madre de Benito, la severa doña Dolores, detectó el romance, por lo que decidió enviarlo a Madrid para alejarlo de Sisita y, de paso, estudiar Derecho, carrera por la que no tenía ninguna vocación ${ }^{10}$. Poco tiempo después, Sisita retornó a Cuba y allí se casó dos veces, la segunda con Pablo Galdós, primo hermano suyo y de Benito por ser hijo del tío Domingo. Pese a esta ruptura, el recuerdo de Sisita permaneció indeleble, dejando un poso de melancolía en el escritor por lo que pudo haber sido y no fue".

Por lo que respecta a su actividad política, el Caribe tiene también un papel destacado. Al menos, en la primera experiencia de Pérez Galdós como parlamentario en las Cortes de la Regencia, inauguradas después del fallecimiento de Alfonso XII en I885. Al año siguiente, don Benito fue elegido diputado liberal por Guayama - Puerto Rico, isla que por cierto jamás pisó-gracias a una decisión personal de Práxedes Mateo Sagasta. Este aceptó la sugerencia del periodista y también diputado José Ferreras - con el que Galdós había coincidido en la Revista de España- y el respaldo entusiasta del ministro de Gobernación, el grancanario Fernando León y Castillo, compañero de clase de Pérez Galdós en el colegio San Agustín en Las Palmas y una de las pocas personas que lo tuteaba ${ }^{12}$. Sobre el terreno puertorriqueño actuó el padre Molera, un enredador sacerdote del Partido Liberal, que consiguió la renuncia del candidato previsto, Sebastián Muñoz Ribera, notario y vicepresidente de la Diputación boricua.

\footnotetext{
${ }^{9}$ En la década de 1840, Cuba sufrió varias revueltas independentistas y un largo levantamiento racial en Matanzas con cuatro mil esclavos alzados. En Trinidad, el ex gobernador Narciso López organizó en 1848 una conspiración conocida como La Mina de la Rosa Cubana. La represión posterior fue muy dura, afectando a varias familias criollas de la alta burguesía trinitaria. Entre ellas, la de la madre de Sisita Galdós, Adriana Tate. Pattison, 1986, pp. 26-28.

10 «Los amores de Galdós. El lado más desconocido del escritor», La Vanguardia, 31 de octubre de 2019.

1 "La novia cubana de Galdós», Carteles, 23 de marzo de 1956.

12 También fueron compañeros de pensión en Madrid durante el primer año de Galdós en la capital. León y Castillo lo introdujo en el ambiente universitario, ya que había llegado un año antes que Benito. Su amistad, sin embargo, pasó por altibajos, aunque nunca llegaron a romper.
} 
La política activa le interesaba poco, pero en 1886 la regencia de la reina María Cristina, unida a un Ejecutivo progresista, anunciaba cambios en España. De modo que Galdós se afilió a los liberales y aceptó el acta de diputado, posición relevante que además le permitiría «hacer amistades [...] Maura, Canalejas o Dato»' ${ }^{13}$, algo que siempre le importó mucho.

Armas Ayala califica esta elección como un «amañado parto electoral [...] Galdós ganó su acta casi por los pelos» ${ }^{14}$. Don Benito, sin embargo, aseguró en sus memorias que había ganado ese escaño gracias a Ferreras - «un amigo mío, de quien he de hablar mucho en el curso de estas Memorias»-, pero yerra al decir que lo consiguió con «un número enteramente fantástico de votos», ya que alcanzó la victoria con una ventaja exigua. En lo que sí acierta el escritor es al decir que: «con estas y otras arbitrariedades llegamos años después a la pérdida de las colonias» ${ }^{15}$.

Don Benito asistía puntualmente a las sesiones de Cortes, pero rehuyó intervenir en el pleno del Congreso ${ }^{16}$ en sus cuatro años como diputado -lo que le valió la pulla de ser uun canario que no canta y un parlamentario que no parla»-y él mismo confesó que votaba todo lo que el Gobierno quería ${ }^{17}$.

Sin embargo, se conoce mucho menos su activa participación en varias comisiones, como la de corrección de estilo del Diario de Sesiones, la del presupuesto general de Puerto Rico o la reforma de la contratación pública en Cuba. Y, por supuesto, su autoría en la redacción del Mensaje de contestación del Congreso al discurso de la reina con motivo del nacimiento de Alfonso XIII, donde Galdós se muestra como un hombre del sistema: «El nacimiento del nuevo Rey [...] ha venido a fortalecer en la conciencia del país la continuidad gloriosa de la secular institución tan firmemente enlazada a la existencia nacional» ${ }^{18}$.

Casualmente o no, en su primera etapa como diputado ingresó en la Real Academia de la Lengua - a la segunda, todo hay que decirlo - apoyado por su amigo Marcelino Menéndez Pelayo.

\footnotetext{
13 Pérez Galdós, 2020, p. 25.

14 Armas Ayala, 1980, p. 106.

15 Pérez Galdós, 2020, p. 18.

${ }^{16}$ Clarín lo atribuye a la timidez de Galdós: «No es capaz de pronunciar cuatro palabras en público [...] Para dar las gracias a una asamblea que le aclama, tiene que sacar del bolsillo un papel en que consta que vivirá eternamente agradecido». Lloréns Bargés, 1980, p. 335.

17 Olmet y García Caraffa, 1912, pp. 48-50.

18 Bellón Fernández, 2018, p. 484.
} 


\section{Cuba en la obra de Benito Pérez Galdós}

Antes de entrar específicamente en Cuba como tema de la producción galdosiana, me permito un apunte introductorio sobre la imagen de América que tenía don Benito y que se manifiesta tanto en su obra periodística como literaria.

En el primer campo, como señala De Armas, el impacto en Galdós fue casi inmediato ${ }^{19}$ y en el novelístico se encuentra, en mi opinión, sobre todo en dos obras: Prim —donde el impulsivo Santiago lbero (qué mordacidad encierra este nombre) quiere reconquistar México- y La vuelta al mundo en La Numancia, ambientada en 1865 en la guerra del Pacífico de España contra Perú y Chile.

Al igual que sucede en ambas novelas con el continente americano, Cuba también queda retratada a través de los arquetipos del terrateniente, del indiano, del esclavista o del militar, pero siempre con la consideración de territorio esencial para la Corona. Tal y como señala Coffey, las Américas -y, por extensión, Cuba - representan para don Benito: «un espacio de riqueza enorme, de territorios extensos con recursos naturales casi infinitos, con la capacidad de influir en la prosperidad de España», tal y como reseñó en 1886 en el madrileño $L a$ Época ${ }^{20}$.

Sin embargo, Pérez Galdós no llegó a escribir el episodio Las colonias perdidas, donde preveía relatar el ambiente social y político cubano previo a la guerra de 1895. Y tampoco otro titulado Cuba, ambientado entre el gran levantamiento secesionista de 1868 y la independencia de 1902 concedida por Estados Unidos después de tres años de protectorado. Solo su fallecimiento impidió a Galdós escribir esta novela, por la que planeó incluso un viaje a La Habana para documentarse, según confesó en una entrevista en 19/4 en la revista La Esfera, de Madrid ${ }^{21}$.

Ciertamente, Galdós no analiza el problema cubano en profundidad, pero sí aparece de manera reiterada en la quinta serie de los Episodios Nacionales, la que discurre entre la Revolución Gloriosa y los primeros años del reinado de Alfonso XII. En especial, en la ya citada Prim (escrita en 1906), pero también en Amadeo I (1910) y De Cartago a Sagunto (I9II), cuando España ya había perdido Cuba ${ }^{22}$.

\footnotetext{
${ }^{19}$ Particularmente, en México, Argentina y Estados Unidos. Armas Galdós, 2015, 372.

${ }^{20}$ Coffey, 2009, p. 710.

21 «Entrevista a don Benito Pérez Galdós», La Esfera, 14 de enero de 1914.

22 Para unos, Cuba era un modo de recomenzar su vida. Así, Alfonso de la Cerda, en la novela Casandra; Víctor, en La de San Quintín, o León, en Mariucha. Para otros, una salida a sus problemas en España (como Melchor Relimpio, en La desheredada), mientras que un tercer grupo lo integran los van y vuelven (por ejemplo, Feijoo en Fortunata y Jacinta).
} 
Su interés por la Isla se centra en dos temas: el autonomismo - y específicamente su desaparición, ya sea para engrosar el independentismo del Partido Revolucionario Cubano o el españolismo de la Unión Constitucional- y el neocolonialismo norteamericano en el Caribe. Según relata en Prim, a principios de 1870 ambos asuntos se debatían abiertamente en el Ateneo de Madrid, donde «había un grupo de cubanos que exponían sus ideas de autonomía y aun de emancipación de las Antillas».

El contrapeso a esta apertura lo encontramos en el periódico El Debate -partidario de Amadeo I y que Galdós dirigió entre 187I y 1873- financiado con capital cubano del esclavista Manuel Calvo y del industrial tabaquero más importante de la Isla, José Gener, además del apoyo político de José Cánovas del Castillo - presidente del Banco Español de Cuba y hermano del líder conservador-.

Durante el Sexenio Revolucionario, los artículos de Pérez Galdós sobre Cuba -por ejemplo, La insurrección cubana, de septiembre de 187I, al hilo de un rebrote de la Guerra Grande-, reducen este conflicto a una simple rebelión de «miserables delincuentes»» ${ }^{23}$. ¿Acaso estamos ante una opinión interesada para ganarse a los dueños del periódico? No lo parece si consideramos que, dos meses después, firmó como director de El Debate un manifiesto condenando la revuelta ${ }^{24}$, y a finales de ese mismo año aceptó como un mal menor el fusilamiento en La Habana de ocho estudiantes de Medicina por una calaverada en un cementerio ${ }^{25}$. Galdós no censuró su ajusticiamiento - excesivo a todas luces y que aún se estudia hoy en los colegios cubanos como símbolo de la resistencia al poder español-, sino que pidió al gobierno civil de la Isla: «más garantías de las que ofrece en la actualidad para la moral pública y los intereses de la nación» ${ }^{26}$.

Dichas garantías debían vigilar especialmente la aplicación de la Ley de Vientres Libres promulgada el año anterior, que concedía la libertad a los hijos nacidos de esclavas y también a todos los esclavos que fueran propiedad del Estado. Con evidente racismo, Galdós escribió: «Hoy no se trata ya solo de la

23 «La insurrección cubana», El Debate, 21 de septiembre de 1871.

24 «A la prensa española», El Debate, 7 de noviembre de 187 I.

${ }^{25}$ Se les acusó de profanar la tumba del periodista asturiano Gonzalo Castañón. En 1890, aún bajo dominio español, se erigió por suscripción un monumento a los estudiantes frente al Morro de La Habana. Todavía hoy se realiza un homenaje cada 27 de noviembre que comienza en la Universidad de La Habana y culmina alrededor del monumento.

26 «La enseñanza en Cuba», El Debate, 27 de diciembre de 1871. 
conservación para España de sus provincias de Cuba y Puerto Rico, sino de impedir que se pierdan también para la civilización, siendo presa de la raza de color que amenaza a la blanca con el exterminio» ${ }^{27}$.

Si buscamos la temática ultramarina en la obra galdosiana ambientada en los años sesenta y setenta del siglo XIX, la encontramos en novelas como Doña Perfecta (1876), Los condenados (1894) o La fiera (1896). Galdós escribió la primera mientras se libra la Guerra Grande cubana (1868-1878) y poco antes de la Paz de Zanjón, que otorgó nuevos derechos políticos a los cubanos. Según Ávila Arellano: «[Doña Perfecta] nace al calor de la confianza que le merecen las actitudes pacificadoras del [general] Martínez Campos, presente en Cuba [...] Esta obra recoge las intenciones regeneracionistas coloniales (tanto morales como administrativas) que proliferaron [en Cuba] en $1876{ }^{28}$. En Los condenados aparece el estereotipo del hacendado patriarcal representado por Santiago Paternoy y en La fiera la figura del militar cruel del absolutista Berenguer - trasunto de Valeriano Weyler, capitán general de Cuba durante la guerra de 1895, que estableció una feroz reconcentración causante de la muerte de miles de civiles-.

También en El abuelo (1897) encontramos metáforas americanas, ya que así podemos entender cómo antiguos sirvientes - símbolo de los independentistas- desplazan al viejo patriarca Rodrigo Arista - que vendría a ser la Corona española - y lo traicionan por dinero - el de los nuevos ricos, los estadounidenses-. Todo esto lleva a Ávila Arellano a afirmar que: «el simbolismo sociopolítico cubano produce sensaciones de agobio y repulsa en el recargado ambiente de ese vergonzante Jesusa [...] o en el inesperado y casi mágico cambio de fortuna de la también decadente Frasquita Juárez» ${ }^{29}$.

En estas tres obras se percibe con nitidez la crisis del país, agravada por la sordera gubernamental hacia el problema cubano, de la que solo se libraban Antonio Maura y León y Castillo, ambos insulares -mallorquín uno, canario el otro-. Estos habían alertado a principios de la década de 1890 contra la caída de la producción agrícola cubana -con las consiguientes huelgas y crecimiento del desempleo-, señalando la ambición norteamericana sobre Cuba - con sus promesas de libertad, república y resurgir económico- como el mayor peligro para la Isla.

El expansionismo norteamericano es el segundo tema de influencia cubana. Un imperialismo que Galdós caracteriza como racista y arbitrario, pero que sin

\footnotetext{
27 «Furor colonial y otros furores», El Debate, 22 de agosto de I87I.

28 Ávila Arellano, 1995, p. 172.

${ }^{29}$ Ávila Arellano, 1995, p. 173.
} 
embargo también presenta efectos positivos, como el ascenso de los nuevos políticos cubanos, a los que don Benito considera más honorables que los especuladores españoles y, por supuesto, que los militarizados estadounidenses.

La necesidad de cambios en las colonias españolas aparece también en su producción teatral, aunque sea de manera velada. Por ejemplo, en Alma y vida (escrita en 1902), donde las ideas reformistas del aguerrido Juan Pablo Cienfuegos triunfan sobre el tiránico patriarcado de Dámaso Monegro. Aunque sea una obra ambientada en el siglo XVIII, se trata de la historia más emotiva dedicada por el escritor al complejo asunto del relevo colonial español en América. Un drama donde la terrateniente Laura de la Cerda, duquesa de Ruydíaz, se erige como imagen de España y termina inmolándose para evitar que sus criados se maten entre sí en otra guerra civil.

La temática cubana también se encuentra en la obra España trágica (1909), ambientada en el convulso año de 1869 mientras el Gobierno Provisional peninsular libra la Guerra Grande cubana, iniciada el año precedente. En ella, el protagonista Vicente Halconero -donde podemos ver al propio Galdós_-declara que la metrópoli debe aceptar la pérdida del continente y también su responsabilidad hacia Cuba. En un momento de gran tensión literaria, Halconero habla de una supuesta carta de Prim al embajador norteamericano, Daniel Sickels, donde aquel sopesaba la venta de Cuba a Estados Unidos, una posibilidad que Halconero/Galdós califica como «maquiavélica». Una vez demostrada la falsedad del rumor - «una ignominia en esta nación romántica, que ha sabido conquistar colonias y perderlas; pero venderlas... no» - ${ }^{30}$, Halconero lee la epístola y confirma que Prim «no es un vendedor de islas, sino el más alto y sagaz de los patriotas [...] un individuo con visión» que, eso sí, duda entre emancipar la Isla o concederle más autonomía.

Al escribir sobre el impacto de la derrota de 1898 ante Estados Unidos, Galdós también muestra una profunda decepción porque a la tragedia humana se une la intoxicación de los partidos políticos y la prensa, poderes que mantuvieron hasta el final la ficción de que España ganaría esa guerra.

Galdós se oponía al conflicto hispano-cubano-americano y pensaba que se debía firmar la paz. En esto conectaba con el sentir mayoritario del pueblo llano gracias a, como señala Max Aub, «una intuición serena, profunda y total de la realidad [española] $)^{3}$. Por eso, pese a ser hijo de un coronel veterano de la guerra de Independencia de 1808 contra Francia, Pérez Galdós pidió la retirada

\footnotetext{
30 Pérez Galdós, 1990, p. 176.

31 Aub, 1966, p. 447.
} 
militar, asunto que le enfrentó a su hermano Ignacio, que había sido oficial voluntario de la Guerra Grande de 1868 y entonces capitán general de Canarias.

La tragedia de España con respecto a Cuba, pensaba Galdós, nacía de la incapacidad popular para seguir el liderazgo del político más clarividente de la segunda mitad del siglo XIX, Juan Prim. El otro gran político era Antonio Cánovas del Castillo, en el poder durante la última guerra cubana, pero que se equivocó al apostar por la solución militar. Por eso, Luis de Zulueta lo considera el reverso de don Benito, ya que representaba todo lo que este rechazaba ${ }^{32}$.

El permanente interés de Galdós por Cuba se intensifica con la pesadumbre por la pérdida de la Isla ${ }^{33}$, aunque no por la independencia en sí -al fin y al cabo, iba a convertirse en una república liberal laica, modelo que Galdós quería para España-, sino por un triple motivo: político - el patriotismo del escritor-, social - su solidaridad con las miles de familias separadas por la guerra-y cultural -el temor a que la ocupación estadounidense de Cuba, iniciada en 1899 y que duró hasta 1902, americanizara la Isla a costa de su «alma española»-.

Así lo manifestó don Benito en 1900 en un discurso recogido por el habanero Diario de la Marina, donde el escritor resaltó las similitudes entre Cuba y Canarias, perdida definitivamente la primera y amenazada de conquista la segunda. Al menos, eso se temía en España ante la voracidad estadounidense ${ }^{34}$, que entonces buscaba una colonia en África:

No se nos arrancará por la fuerza [ni a cubanos ni a canarios] del tronco robusto al que pertenecemos [la cultura hispánica] [...] No creamos ni aun en la posibilidad de que pueda haber una mano extranjera con poder bastante para cortarnos 0 desgajarnos [de la herencia española] ${ }^{35}$.

La responsabilidad del desastre humano de la guerra de Cuba correspondía, por supuesto, al Gobierno, con independencia de que lo dirigieran los liberales o los conservadores - «dos manadas de hombres que no aspiran más que

32 «Quería Cánovas un pueblo sin grandes conflictos espirituales. Galdós lleva hasta el pueblo los grandes conflictos espirituales. Cánovas cierra el siglo XIX, Galdós inicia el XX. Cánovas, orador, ejercía el Poder [...] en la España oficial. Galdós, taciturno, la coalición de las oposiciones extremas del Parlamento». «La resurrección de Galdós. El hombre nuevo del tiempo viejo», Diario de Las Palmas, 29 de enero de 193I.

33 Según Ortiz-Armengol, «[Galdós] hubo de sentir muy vivo el dolor de esta humillación: la más dura de la historia de España. Su amargura tenía que estar aumentada por la vinculación de su familia con la tierra cubana desde el Hurtado de Mendoza defensor de La Habana hasta los hermanos de emigración reciente». Ortiz-Armengol, 2000, p. 365.

${ }^{34}$ En esa época, Estados Unidos también quería estar presente en África. Este continente había sido repartido entre las potencias europeas en la Conferencia de Berlín de 1884, donde los norteamericanos asistieron como invitados. En 1898, Washington valoró la posibilidad de arrebatar las Canarias a España, un enclave estratégico para expandirse por el occidente africano a costa de alguna potencia colonial secundaria como Bélgica, Italia o Portugal.

35 Diario de la Marina, I de enero de 190 I. 
a pastar en el presupuesto»-, como escribió en Cánovas. La Restauración, pensaba Galdós, había sido la causante del fracaso porque la monarquía se había convertido en «un poder arbitrario que acopla el Trono y el Altar, para oprimir a ese pueblo infeliz y mantenerlo en la pobreza y la ignorancia», decía en España $\sin \operatorname{Rey}^{36}$.

Pese a ser consciente del coste humano de las guerras cubanas, él alzó poco la voz para denunciar una derrota que también percibió como una humillación - sentimiento compartido por la inmensa mayoría del país-. Si bien en la novela Lo prohibido (1884) utiliza al soez personaje Alejandro Sánchez Botín para desvelar «una política hacia Cuba basada en la rapiña y el robo»» ${ }^{37}$, la capitulación ante las fuerzas cubano-americanas es más dolorosa por los lazos familiares tejidos con Cuba durante tres generaciones.

La pérdida de los territorios ultramarinos sumió a España en una depresión, también por la influencia de la autocompasión noventayochista, que Galdós despreciaba. $Y$ ante el derrotismo, instó a «una reflexión sobre las causas de la decadencia española ${ }^{38}$. Es decir, la independencia cubana era un hecho lamentable porque suponía la amputación de una parte de España, pero debía superarse impulsando la regeneración nacional: desarrollo económico, republicanismo, divulgación del pensamiento moderno y modernización industrial. Para lograrlo, había que atajar el caciquismo y crear una red de escuelas públicas de educación primaria que solucionara el analfabetismo de la mitad de la población ${ }^{39}$.

Lo explica su discurso del 9 de diciembre de 1900 en un homenaje que le brindó la colonia canaria en el Café Inglés de Madrid por el final de la tercera serie de los Episodios Nacionales, escrita en apenas dos años ${ }^{40}$. Ahí Galdós ensalzó la potencia del alma española y demuestra que todavía siente la pérdida de Cuba, a que la considera parte integral de España:

En nosotros vive y vivirá siempre el alma española, y hoy más que nunca es necesario que así se diga [...] Tengamos fe en nuestros destinos. [...] Ahora que la fe nacional parece enfriada y oscurecida, [...] demos el ejemplo de confianza en el porvenir. [...] De este modo contribuiremos a formar lo que hace tanta falta: la fe

\footnotetext{
${ }^{36}$ Una de sus acusaciones más conocidas fue el artículo «Soñemos, alma, soñemos». Publicado el 8 de noviembre de 1903 en el primer número de la revista Alma española (fundada por el propio Galdós) presenta un tono bastante unamuniano: «El país se ha mirado en el espejo de su conciencia, horrorizándose de verse compuesto de un rebaño de analfabetos conducido a la miseria por otro rebaño de abogados».

37 Pérez Galdós, 200I, p. 27.

38 Cánovas Sánchez, 2019, p. 283.

${ }^{39}$ En 1900, el 57 por ciento de la población española no sabía leer. De Gabriel, 1997, pp. 217-243.

${ }^{40}$ Entre 1898 y 1900 publicó diez novelas. Solo en este último año de 1900, tres: Montes de Oca, Los Ayacuchos y Bodas reales.
} 
nacional. Cada cual en su esfera, grande o chica, debe ayudar a formarla y robustecerla, pues sin esa gran virtud no hay salvación posible para las naciones ${ }^{41}$.

Esta posición influyó en el manifiesto del Grupo de los Tres -Pío Baroja, Ramiro de Maeztu y el inventor del término, José Martínez Ruiz (aún no utilizaba el pseudónimo Azorín) - publicado a finales de $190 \mathrm{I}$ y origen del discutido término de Generación del 98.

Ellos, al igual que Pérez Galdós - «nuestro mentor y patriarca», según lo llamaba Azorín-, creían en la europeización de España y en las soluciones científicas a las «llagas sociales» - las principales, la pobreza y el hambre-. Sin embargo, el canario censuraba su indiferencia por la ruptura de España, asunto intranscendente para los noventayochistas - si es que existieron alguna vez-y del que apenas escribieron algún artículo periodístico o libelo irrelevante ${ }^{42}$.

Pese a esta clarividente opinión, sus intervenciones como diputado republicano en las legislaturas de 1907, 1910 y 1914, no aluden a la situación de Cuba y esto resulta sorprendente si tenemos en cuenta la nutrida colonia hispanocubana, donde los canarios formaban el tercer grupo más numeroso por detrás de gallegos y asturianos. En particular, en la última legislatura, donde de nuevo resultó elegido por Las Palmas con los reformistas de Melquiades Álvarez ${ }^{43}$ pese a llevar diecisiete años sin pisar el archipiélago. Una vez más, León y Castillo jugó de nuevo un papel clave para su elección, algo que el propio escritor le reconoció en 1914 en un carta personal ${ }^{44}$.

Por segunda vez, Galdós aceptó convertirse en un diputado cunero - un paracaidista, diríamos hoy - designado desde Madrid y poco combativo, en esta ocasión debido a su avanzada edad y la ceguera que limitaba notablemente su vida cotidiana. Una imagen muy alejada del aguerrido Galdós de las dos últimas décadas de siglo XIX, enfrentado a los poderes fácticos y que ha cristalizado en la historia gracias a opiniones como la expresada en La familia de León Roch, novela de 1878 ambientada al final de la Guerra Grande, a la que considera un conflicto imperial desastroso 45 .

Ahora bien, las mejores páginas de Pérez Galdós sobre Cuba las encontramos en la prensa, que fue el altavoz preferido del escritor canario y la tribuna

41 Pérez Galdós, 2013, pp. 24-25.

42 Comparto la opinión de Pedro Pascual de que unir la generación del 98 con la pérdida de las colonias es indefendible. Pascual Martínez, 2000, p. 345.

${ }^{43}$ Esta elección viene ampliamente documentada en Navarro Ruiz, 1933, pp. 30I-304. También, Béthencourt, 1993, pp. 35I-363.

44 «Agradezco vivamente tu intervención decisiva en este asunto de mi triunfante candidatura», Pérez García, 2018, p. 32.

${ }^{45}$ Sinningen, 1998, p. 116. 
desde la que hizo más política, pero con la ventaja del derecho a contradecirse -aspecto muy afín al carácter de Galdós-movido de «un sentimiento [...] considerado una antigualla: el Patriotismo» ${ }^{46}$. Este sentimiento patriótico le hará replantearse al final su admiración teórica por el socialismo -al que consideraba a principios de siglo: «una idea sincera, sincerísima. Es la última palabra en la cuestión social [...] Por ahí es por donde llega la aurora»— ${ }^{47}$, pero apartándose de la revolución marxista y apostando por una alianza de los intelectuales, la burguesía liberal y el proletariado para progresar hacia un futuro donde estuvieran «armónicamente conectadas las tres ruedas de la actividad humana: Arte, Capital y Trabajo» ${ }^{48}$. ¿Bajo qué ideología? ¿En qué formación política? En el republicanismo del Partido Reformista del gijonés Melquiades Álvarez, del que Galdós llegará a ser presidente de honor y al que se unieron en 1912 personajes de la talla de Manuel Azaña, Pedro Salinas o José Ortega y Gasset.

Esta postrera opción política - dispuesta a aceptar la monarquía como un mal menor llamado a desaparecer- le permitirá conservar lo que José-Carlos Mainer denomina «los tres antis de Galdós»: anticaciquismo (presente en Doña Perfecta, 1876), anticlericalismo (con su culmen en Electra, I90 I) y antimilitarismo (Aita Tettauen, 1906), a los que responsabilizaba de los males de la patria ${ }^{49}$. Él, como siempre afirmó, «amaba la realidad» $\aleph^{50}$ y su curiosidad mental por lo extranjero lo convirtió en un hombre de vanguardia al que, según Azorín, «el Desastre, fracaso de toda la política española, ha avivado su sensibilidad y ha puesto en ella una variante que antes no había en España» ${ }^{51}$.

Una variante librepensadora, podemos añadir, que aspiraba a terminar con el turnismo como sistema político porque solo beneficiaba a la élite dirigente -ya fuera liberal o conservadora, laica o tradicionalista- y que, si bien otorgaba estabilidad al régimen, exigía pagar un precio inaceptable: la manipulación electoral.

¿Qué alternativa propusieron a partir de entonces los intelectuales? El regeneracionismo, que surgió como una respuesta moral a la corrupción política concretada en una amplia reforma agraria, el reforzamiento del Estado a costa del clientelismo rural y una legislación laboral garantista. Galdós respaldó estas propuestas, ya formuladas por Joaquín Costa en 1901 en su libro Oligarquía y caciquismo. De hecho, Costa remitió al escritor canario un ejemplar antes de su

\footnotetext{
46 Dos años antes, en 1906, se lo había contado a su amigo Alfredo Vicenti, periodista gallego y director de El Liberal. Armas Ayala, 1990, p. 483.

47 Olmet y García Caraffa, 1912, p. III.

48 «El Primero de Mayo», Nueva España, I de mayo de 1907.

49 Mainer, 2010, p. 125.

50 Celma Valero, 1995, pp. 49-50.

51 Azorín, 196I, p. 27.
} 
publicación para que le diera su opinión. Según Cánovas Sánchez, «Galdós compartió su diagnóstico y sus propuestas de solución. Los intelectuales, pensaban los dos, tenían que movilizarse para romper la malla que frenaba el progreso de España» ${ }^{52}$.

Los regeneracionistas veían en la derrota colonial una oportunidad para acelerar los cambios hacia una verdadera democracia basada en la justicia social y en un Estado eficaz y neutral. Solo así terminarían las «querellas chabacanas» y el «olor cadavérico» en los que se engolfaban el gobierno, los partidos, la prensa y todos los poderes públicos. Esta afirmación se glosa en extenso en Cánovas, el último de los Episodios Nacionales, publicado en 1912 pero que recoge el ideario galdosiano de fin de siglo.

Galdós reconocía la existencia de algunos «políticos puros» que sí se esforzaban en crear un Estado moderno, «administrador de lo nuestro, regulador de la vida de relación humana», pero no «principio vital, [...] y menos nodriza», apartándose así del estatalismo socialista.

Conseguirlo liberaría las fuerzas ocultas «bajo la corteza del mundo oficial», potencias que Galdós veía «en ignición creciente, que es el ser de la nación». Y debo añadir: no solo de la nación española, sino también de las repúblicas americanas, entre las que Cuba ocupaba un lugar señero por su independencia.

A nivel personal, la primera década del siglo XX fue dolorosa. En 1905 falleció su hermano Ignacio y al año siguiente el escritor José María Pereda, uno de sus amigos más cercanos pese a estar en las antípodas políticas, ya que era carlista. Con ambos había compartido mucho tiempo en Santander, ciudad en la que recibió la noticia, en el verano de 1906, del suicidio en Madrid de Lorenza Cobián, la madre de su hija María y modelo pictórico de Sorolla, al parecer inspiradora del enérgico personaje de Fortunata en Fortunata y Jacinta $\left(\right.$ (887) ${ }^{53}$. Por último, su situación económica empeoró porque, si bien ganó mucho dinero, siempre fue un manirroto, endeudado con su finca santanderina de San Quintín y haciendo frente a las pérdidas de su editorial, que se empeñaba en mantener abierta contra viento y marea.

¿Y qué decía de América en aquellos años finales de su vida? Propone un retorno de los indianos a España para que, con su empuje y visión del mundo, trajeran lo mejor de la modernidad americana, como escribió en La Esfera: «Es América, es América, la civilización [...] que ahora, con filial generosidad, a su vez nos conquista trayéndonos los laureles más preciosos: el bienestar, la cultura

52 Cánovas Sánchez, 2019, p. 289.

53 El Cantábrico, 26 de julio de 1906. Este diario recoge un intento de suicidio en la estación de tren de Príncipe Pío. Al fracasar, y debido al caos que provocó, fue detenida en el Gobierno Civil, donde se ahorcó. Al parecer, padecía psicosis paranoica. Ortiz-Armengol, 2000, pp. 438-439. 
y la paz» ${ }^{54}$. Y, de toda América, Cuba era el mejor referente, el más cercano y donde existía una extensa comunidad de españoles.

\section{CONCLUSIONES}

Como hemos visto, Cuba aparece en las obras de Galdós desde el principio de su producción literaria y periodística, algo inaudito en sus contemporáneos ${ }^{55}$.

Su interés por la Isla es permanente, ya la retrate como una pieza menospreciada de la sociedad española o bien como un verdadero destino de futuro. Más atento al trasfondo moral de los hechos que allí suceden que a los hechos mismos, por más que estos impacten en la sociedad peninsular, de ordinario ignorante de lo que ocurría en aquel territorio salvo que hubiera guerra. ¿Quizá esta indiferencia explique la pérdida de Cuba, tan costosa en medios humanos y materiales y tan profunda en la conciencia nacional?

Benito Pérez Galdós convierte a Cuba en una tierra de ideales, los mismos que tuvo España en América durante tres siglos, pero que abandonó a la fuerza, perdiendo así su principal fuente de riqueza ${ }^{56}$. Entre un sabio que no quiso (Cánovas) y un valiente que no pudo (Sagasta), el desastre terminó llegando para la vieja España. Sin embargo, ese desastre alumbró unas repúblicas hispanoamericanas convertidas a finales de siglo en «países jóvenes donde hay vida. Aquí [España] todo está muerto. Aquí tiene que haber una gran catástrofe o esto desaparecerá por putrefacción $»^{57}$.

Cuba es el episodio final de la tragedia española, aunque también tuvo efectos positivos para la propia España. Sobre todo, el decidido impulso al regeneracionismo, bandera que el escritor grancanario enarbolaba desde antes de la crisis de 1898. En este sentido, como apunta Mainer, Galdós era lo más cercano a un escritor con una visión nacional capaz de descubrir las emociones populares, como antes Dickens en Inglaterra y Hugo en Francia o su contemporáneo Tólstoi en Rusia ${ }^{58}$.

A partir de 1899, cuando la Restauración se tambaleaba, los nacionalismos periféricos acosaban al Estado y la Nación dudaba de sí misma, Galdós reanuda los Episodios Nacionales y obtiene clamorosos éxitos teatrales. El cambio del siglo

\footnotetext{
54 «España y América», La Esfera, 13 de mayo de 1914.

55 Quizá con las salvedades de Emilio Castelar, Juan Valera y Marcelino Menéndez Pelayo, pero ocupándose estos de América en sentido amplio, no de Cuba específicamente.

56 Un buen análisis sobre América en la obra de Galdós en Troncoso, 2017, pp. 429-436.

57 Pérez Galdós, 2006, p. 70.

58 Mainer, 20I4, p. 494.
} 
XIX al XX, cuando aún no había cumplido los sesenta años, supone una decidida renovación de una idea persistente: la libertad. La libertad de los hombres - y las mujeres, sobre las que recaería el peso de la reforma social - para vivir sus vidas como más les plazca. La libertad de los pueblos para escribir su futuro y, por supuesto, la libertad de pensamiento, de asociación o de expresión. Todo ello teñido de un vitalismo y una confianza en el futuro que ya no se atenuó.

Alrededor de los cincuenta años de edad, Galdós experimentó una radicalización ideológica, que también afectó a su visión de la política, tanto en América como en África. Por eso se unió a los que pedían el abandono de los territorios españoles de Marruecos, Guinea y el Sáhara y un acercamiento a las repúblicas hispanas. ¿Con qué fórmula? Una unión iberoamericana, que fomentara la unidad comercial, cultural y espiritual de España con los antiguos territorios de ultramar. Con este viraje ideológico de don Benito - que eminentes galdosistas ubican entre 1899 y $1906^{59}$ - comienza su cambio de actitud hacia Cuba.

La idea no era originalmente suya, pero su respaldo sí resultó importante, ya que Galdós pensaba que los lazos con los «hermanos americanos» no se mantendrían solo con la lengua o la religión. En este punto, encontró el apoyo de los que aún creían en una reunificación con las naciones hispánicas y para la que esa unión espiritual podía suponer un paso previo a la reincorporación. El ejemplo de la República Dominicana, que después de diecisiete años de independencia había pedido en 1861 su reintegración en la metrópoli60, confirmaba esa esperanza.

Con la llegada del nuevo siglo también cuaja una de convicciones más persistentes: la superioridad de la economía y la industria sobre la tradición y la historia, llaves que abren la puerta del futuro de la nación, donde las repúblicas iberoamericanas rescatarán con su vitalidad a una España sumida en el marasmo. La modernidad española, en síntesis, pasaba por aprovechar la oportunidad de haberse librado de un imperio moribundo que era incapaz de defender.

En el caso concreto de la Cuba que luchó medio siglo por independizarse, Galdós comparte la opinión mayoritaria de la sociedad española: se trataba de un lugar para hacer fortuna, pero siempre con el anhelo de volver a España -a poder

\footnotetext{
59 Para Carlos García Barrón es evidente desde La vuelta al mundo de la Numancia (I906): «Para entonces, Galdós es un decidido republicano, muy consciente de la descomposición nacional agudizada por el desastre de 1898», García Barrón, 1986, p. 147. Armas, 2015, p. 390, lo adelanta a Vergara, escrita en I899. Esta me parece una interpretación forzada, ya que Pérez Galdós aún estaba a la expectativa acerca de si Alfonso XIII -todavía menor de edad- se iba a convertir en un rey liberal y modernizador.

${ }^{60}$ Entre 186I y 1865, España controló Republica Dominicana, donde estableció una nueva capitanía general. La resistencia interna de una facción del ejército isleño y la formulación de la doctrina Monroe («América para los americanos») por parte de Estados Unidos forzó la retirada española.
} 
ser, enriquecido-, pero también una oportunidad para eludir a los acreedores, esquivar a la justicia $o$ ascender en el Ejército.

El mejor resumen a esta cosmovisión lo encontramos en el capítulo ocho de O'Donnell (1904) cuando el astuto marqués de Beramendi -señorito alcarreño y personaje principal- aconseja al crápula Aransis que emigre a La Habana, se case con una rica heredera ("género que allí abunda») y solvente todos sus problemas financieros. Al fin y al cabo, Cuba era una provincia como cualquier otra y emigrar allí no estaba mal visto como sí hacerlo a México o Argentina, naciones hostiles:

En España tenemos un medio seguro de aliviar la desgracia de los que [...] pierden su hacienda. Se les manda a Cuba con un buen destino, y allí se arreglan para recobrar lo que aquí se les fue entre los dedos. España [...] posee un heroico bálsamo ultramarino para los males de la patria [...] No te me subas a la parra de la dignidad. [...] Mira las cosas por el lado práctico, que suele ser el lado más bonito; no desprecies los ingenios, los potreros y los cafetales, que para ti reserva la virgen América.

Es el momento en el que Galdós manifestó su deseo de conocer Cuba, «una tierra tan cercana a todos nosotros, por vinculación familiar y sentimental» y que confirma una evolución de su pensamiento hacia la Isla. Así se lo manifestó en 1914 al director del habanero El Fígaro en una carta personal o en 1916 en una entrevista en La Montaña - publicación de la Sociedad Montañesa de Beneficencia de La Habana - con su buen amigo el periodista José Estrañi:

Soy un entusiasta admirador de aquella tierra de ensueño y poesía. Cuba. [...] iQué no sacrificaría a cambio de una visita a aquellos compatriotas! [...] Tiempo hace que acaricio como una necesidad la visita a la perla antillana, pero el exceso de trabajo primero, $y$ mis ojos enfermos ahora, me impiden por el momento realizar esta esperanza de largos años. [...] Para escribir Cuba poseo apuntes y datos en abundancia, y si algún día éstos pobres ojos míos pueden guiarme, iréé.

Con Muñoz Molina ${ }^{62}$ podemos decir, en síntesis, que el pasado que le importaba a Galdós era aquel que se extendía hasta el presente inmediato. El que aún estaba dentro de los límites de la memoria viva, aunque ya en el filo de su disolución. Y le importaba por razones muy prácticas, de una extrema urgencia vital y política. Quería comprender su tiempo y lo consiguió.

\footnotetext{
${ }^{61}$ Su vinculación con Cantabria comienza en I87I, año en el que empezó a veranear en Santander. Se reforzó con el nombramiento de su hermano Ignacio como gobernador militar de esa provincia en 1879 y con la compra de la finca San Quintín, única casa que tuvo en propiedad en toda su vida. «Entrevista en San Quintín a don Benito Pérez Galdós», La Montaña, II de noviembre de 1916.

62 «El país de Galdós», El País, 10 de septiembre de 2011 .
} 
CUBA, GALDÓS Y LA CRISIS DEL 98

\section{BIBLIOGRAFÍA}

Aguilera y Arjona, Alberto, «Alocución de Galdós», El Liberal, Madrid, 9 de diciembre de 1909.

Alonso Baquer, Miguel, «l898. El ejército español en Cuba», Militaria, 13, 1999, pp. 17-21.

Arencibia, Yolanda, Galdós. Una biografia, Barcelona, Tusquets Editores, 2020.

Armas Galdós, Frederick A. de, «Una rama de la familia Galdós en Cuba: Genealogía e influencia», en Galdós y la gran novela del siglo XIX. Actas del IX Congreso Internacional Galdosiano, eds. Y. Arencibia y R. M. Quintana, Las Palmas de Gran Canaria, Ediciones del Cabildo Insular de Gran Canaria, 20I I, pp. 787-796.

Armas Galdós, Frederick A. de, «Una conversación trasatlántica: Benito Pérez Galdós y Domingo A. Galdós en La estrella de Panamá (I889-190I)», Revista de Literatura, LXXVII, I54, 2015, pp. 37I-397.

Armas Ayala, Alfonso, «Galdós, diputado por Puerto Rico», en Actas del Segundo Congreso Internacional de Estudios Galdosianos. II, ed. Jesús Bombín Quintana, Las Palmas de Gran Canaria, Ediciones del Cabildo Insular de Gran Canaria, 1980, pp. 103-1II.

Armas Ayala, Alfonso, «Galdós y la política», en Actas del Tercer Congreso Internacional de Estudios Galdosianos. II, ed. Jesús Bombín Quintana, Las Palmas de Gran Canaria, Ediciones del Cabildo Insular de Gran Canaria, 1990, pp. 475-487.

Artiles, Joaquín, «Don Domingo Galdós de Alcorta y doña María de la Concepción Medina, abuelos de Pérez Galdós», Anuario de Estudios Atlánticos, 13, 1967, pp. 157-179.

Ávila Arellano, Julián, «El desastre del 98 en la obra de Benito Pérez Galdós», en Actas del Quinto Congreso Internacional de Estudios Galdosianos. II, ed. Jesús Bombín Quintana, Las Palmas de Gran Canaria, Ediciones del Cabildo Insular de Gran Canaria, 1995, pp. 165-175.

Bellón Fernández, Juan José, «Textos políticos de Benito Pérez Galdós publicados en prensa», en Memoria del XI Congreso Internacional de Estudios Galdosianos. La hora de Galdós, ed. Yolanda Arencibia et al., Las Palmas de Gran Canaria, Ediciones del Cabildo de Gran Canaria, 2018, pp. 48I-508.

Béthencourt Massieu, Antonio de, «Don Benito Pérez Galdós diputado por Gran Canaria en 1914», en Actas del Cuarto Congreso Internacional de Estudios Galdosianos. II, ed. Jesús Bombín Quintana, Las Palmas de Gran Canaria, Ediciones del Cabildo Insular de Gran Canaria, 1993, pp. 35I-363.

Bueno, Salvador, «La novia cubana de Galdós», Carteles, La Habana, 23 de marzo de 1956

Camacho Pérez-Galdós, Guillermo, «Ascendencia de los Pérez Galdós. Estudio especial de las ramas cubanas de esta familia», Anuario de Estudios Atlánticos, I, 19, 1973, pp. 575-629.

Cánovas Sánchez, Francisco, Benito Pérez Galdós. Vida, obra y compromiso, Madrid, Alianza Editorial, 2019.

Celma Valero, María Pilar, «¿Generación del 96, del 98 o Modernismo?», Castilla. Estudios de Literatura, 20, 1995, Pp. 47-54.

Coffey, Mary L., «Las colonias perdidas: un episodio nacional que no escribió Galdós», en Galdós y el siglo XX. Actas del VIII Congreso Internacional de Estudios Galdosianos, eds. Yolanda Arencibia et al., Las Palmas de Gran Canaria, Ediciones del Cabildo Insular de Gran Canaria, 2009, pp. 704-7I3.

Dean-Thacker, Verónica P., Galdós político, Las Palmas de Gran Canaria, Real Sociedad Económica de Amigos del País de Gran Canaria, 1992.

Estrañi, José, «Entrevista en San Quintín a don Benito Pérez Galdós», La Montaña, I I de noviembre de |9|6.

Fernández Cordero, Carolina, Ideología y novela en Galdós (1901-1920), Madrid, Universidad Autónoma de Madrid, 2014.

Fuentes, Víctor, Galdós demócrata y republicano (escritos y discursos 1907-1913), Santa Cruz de Tenerife, Editorial Universidad de La Laguna/Ediciones del Cabildo Insular de Gran Canaria, 1982.

Gabriel Fernández, Narciso de, «Alfabetización y escolarización en España (I887-1950)», Revista de Educación, 314, 1997, pp. 217-243.

García, Fernando, «Los amores de Galdós», La Vanguardia, 31 de octubre de 2019.

García Barrón, Carlos, «América en Galdós», Anales de Literatura Española, 5, 1986, pp. I45-152.

González Fiol, Enrique, «Benito Pérez Galdós (confesiones de su vida y de su obra)», Por esos Mundos, Madrid, 21 de junio de 1910.

Guanche, Jesús, Procesos etnoculturales en Cuba, La Habana, Ed. Letras cubanas, 1983.

Hidalgo, Manuel, «Leer a Galdós: El amigo Manso», El Cultural, I5 de noviembre de 2019.

Lloréns Bargés, César, «El diputado Pérez Galdós», en Actas del Segundo Congreso Internacional de Estudios Galdosianos, ed. Jesús Bombín Quintana, Las Palmas de Gran Canaria, Ediciones del Cabildo de Gran Canaria, 1980, pp. 329-340. 


\section{CUBA, GALDÓS Y LA CRISIS DEL 98}

Machado González, Bruno Javier, Orujo de memorias. Presencia e impronta de la emigración cántabra a Cuba, Vigo, Grupo de Comunicación Galicia en el Mundo, 2009.

Mainer, José-Carlos, «Galdós, escritor del siglo XX», en Miscelánea de estudios en homenaje a Guillermo Fatás Cabeza, ed. Antonio Duplá Ansuategui et al., Zaragoza, Institución Fernando el Católico, 2014, pp. 489-497.

Mesa, Rafael de, Don Benito Pérez Galdós. Su infancia, sus mocedades, su senectud, Madrid, Imprenta Juan Pueyro, 1920.

Muñoz Molina, Antonio, «El país de Galdós», El País, Madrid, 10 de septiembre de $201 \mathrm{I}$

Navarro Ruiz, Carlos, Páginas históricas de Gran Canaria, Las Palmas de Gran Canaria, Tipografía Diario, 1933.

Antón del Olmet, Luis y Arturo García Caraffa, Los grandes españoles. Galdós, Madrid, Imprenta Alrededor del Mundo, 1912.

Ortiz-Armengol, Pedro, Vida de Galdós, Barcelona, Planeta de Libros, 2000.

Pacheco González, María Caridad, «Visión martiana de Benito Pérez Galdós», Revista Estudios, 30, 20I5, PP. 207-228.

Pascual Martínez, Pedro, «Galdós, los escritores y el 98», en Actas del XIII Congreso de la Asociación Internacional de Hispanistas. Vol. 2, ed. Florencio Sevilla Arroyo y Carlos Alvar Ezquerra, Madrid, Castalia, 2000, pP. 344-352.

Pattison, Walter T., «Los Galdós en Cuba. La primera generación», Anales galdosianos, 21, 1986, pp. I5-32.

Pérez Galdós, Benito, «Furor colonial y otros furores», El Debate, 22 de agosto de 187I.

Pérez Galdós, Benito, «La insurrección cubana», El Debate, Madrid, 2 I de septiembre de I87I.

Pérez Galdós, Benito, «A la prensa española», El Debate, 7 de noviembre de I87I.

Pérez Galdós, Benito, «La enseñanza en Cuba», El Debate, 27 de diciembre de I87I.

Pérez Galdós, Benito, «Cuba-Filipinas», La Prensa, Buenos Aires, 9 de noviembre de 1884

Pérez Galdós, Benito, «Soñemos, alma, soñemos», Alma española, I, Madrid, 8 de noviembre de 1903.

Pérez Galdós, Benito, «España y América», La Esfera, Madrid, I3 de mayo de 1914.

Pérez Galdós, Benito, Lo prohibido, Madrid, Cátedra, 200I.

Pérez Galdós, Benito, El caballero encantado, Madrid, Ediciones Akal, 2006.

Pérez Galdós, Benito, «La fe nacional», en La fe nacional y otros escritos, Madrid, Rey Lear, 2013.

Pérez Galdós, Benito, Correspondencia, Madrid, Ediciones Cátedra, 2015.

Pérez Galdós, Benito, Memorias de un desmemoriado, Madrid, El Nadir Ediciones, 2020.

Pérez García, José Miguel, «Galdós y León y Castillo», en Memoria del XI Congreso Internacional de Estudios Galdosianos. La hora de Galdós, ed. Yolanda Arencibia et al., Las Palmas de Gran Canaria, Ediciones del Cabildo de Gran Canaria, 2018, pp. 17-34.

Río, Ángel del, «Notas sobre el tema de América en Galdós», Nueva Revista de Filología Hispánica, XV núm. I, 1961, pp. 279-296.

Rovira Martínez de Contrasta, María Isabel, Los aprendizajes de Benito Pérez Galdós: del periodista político al novelista en ciernes (I865-/876), Barcelona, Universidad de Barcelona, 2017.

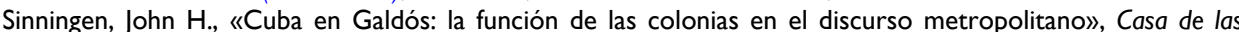
Américas, 212, 1998, pp. II5-121.

Sinningen, John H., «Un signo cambiante: Cuba en Galdós y en nuestros tiempos», en Morada de la palabra. Homenaje a Luce y Mercedes López-Baralt. II, ed. William Mejías López, San Juan de Puerto Rico, Ediciones Universidad de Puerto Rico, 2002, pp. I553-I565.

Troncoso Durán, Dolores, «Las colonias en los Episodios galdosianos», Letras de Hoje, 52, 4, Porto Alegre, 2017, pp. 429-436.

Viñalet, Ricardo, «De la percepción galdosiana en Cuba», en Actas del IX Congreso Internacional de Estudios Galdosianos, ed. Yolanda Arencibia y Rosa M. Quintana, Las Palmas de Gran Canaria, Ediciones del Cabildo de Gran Canaria, 201 I, pp. 700-707.

Zulueta, Luis de, «La resurrección de Galdós. El hombre nuevo del tiempo viejo», Diario de Las Palmas, 29 de enero de 1931. 